LINHARES, Rafaela Rovani de; AQUINO, Sergio Ricardo Fernandes de. Mediação e Sustentabilidade: por uma cultura da cooperação a partir dos objetivos do desenvolvimento sustentável. Revista Eletrônica Direito e Política, Programa de Pós-Graduação Stricto Sensu em Ciência Jurídica da UNIVALI, Itajaí, v.13, n.3, $3^{\circ}$ quadrimestre de 2018. Disponível em: www.univali.br/direitoepolitica - ISSN 1980-7791

\title{
MEDIAÇÃO E SUSTENTABILIDADE: POR UMA CULTURA DA COOPERAÇÃO A PARTIR DOS OBJETIVOS DO DESENVOLVIMENTO SUSTENTÁVEL
}

\author{
MEDIATION AND SUSTAINABILITY: FOR A CULTURE OF COOPERATION FROM \\ THE OBJECTIVES OF SUSTAINABLE DEVELOPMENT
}

Rafaela Rovani de Linhares ${ }^{1}$

Sergio Ricardo Fernandes de Aquino²

SUMÁRIO: Introdução; $1 \mathrm{~A}$ importância da sustentabilidade no século XXI a partir dos Objetivos do Desenvolvimento Sustentável - ODS; 2 A face da socialidade da mediação; 3 Mediação e Sustentabilidade: a cooperação viva pelo significado do Objetivo n. 15 dos Objetivos do Desenvolvimento Sustentável; Considerações finais; Referências das fontes citadas.

\section{RESUMO}

Este artigo científico tem como objetivo geral avaliar como a Mediação e a Sustentabilidade trazem significado ao n. 15 dos Objetivos do Desenvolvimento Sustentável, ao se consolidar a cultura da cooperação, para relacionar as diretrizes da Mediação e Sustentabilidade como forma de materialização da cooperação. A pesquisa desenvolve-se na fase de investigação e relato do estudo, pelo método Indutivo e na fase de tratamento de dados, pelo método Cartesiano. Pode-se verificar que, dentre as formas jurídicas de se permitir o aperfeiçoamento de uma convivência pacífica, seja pela via institucional ou não, tem-se a alternativa da Mediação. Se o foco da Mediação é a Pessoa, percebe-se que a resolução de conflitos não ocorre pela imposição da vontade estatal, mas pelas vontades que convergem em solucionar as suas dificuldades. Por esse motivo, a atitude empreendida pela Mediação não se exaure nesses espaços dialogais, porém se ampliada para a vida cotidiana, pode se consolidar uma cultura da cooperação.

Palavras-chave: Mediação; sustentabilidade; cooperação.

\footnotetext{
${ }^{1}$ Acadêmica de Direito IMED. E-mail: rafaelarovani@hotmail.com

2 Doutor e Mestre em Ciência Jurídica - UNIVALI. Professor Titular e Pesquisador do Programa de Mestrado em Direito da IMED. Coordenador do Grupo de Pesquisa "Ética, Cidadania e Sustentabilidade". E-mail: sergiorfaquino@gmail.com
} 
LINHARES, Rafaela Rovani de; AQUINO, Sergio Ricardo Fernandes de. Mediação e Sustentabilidade: por uma cultura da cooperação a partir dos objetivos do desenvolvimento sustentável. Revista Eletrônica Direito e Política, Programa de Pós-Graduação Stricto Sensu em Ciência Jurídica da UNIVALI, Itajaí, v.13, n.3, $3^{\circ}$ quadrimestre de 2018. Disponível em: www.univali.br/direitoepolitica

- ISSN 1980-7791

\section{ABSTRACT}

This paper has as general objective to evaluate how Mediation and Sustainability bring meaning to $n .15$ of the Sustainable Development Objectives, to reassure cooperation as guidelines of Mediation and Sustainability. The study is developed, in research and reporting phase, by the Inductive method and in the data treatment phase, by the Cartesian method. It can be verified that, among the juridical forms to improve a peaceful coexistence, whether through the institutional path or not, we have the alternative of Mediation. If Mediation focus on Persons, the resolution of conflicts does not occur by the imposition of the State's will, but by the wills of people to solve their difficulties. For this reason, the attitude undertaken by Mediation is not exhausted in these dialog spaces, but if extended to everyday life, a culture of cooperation is possible.

Keywords: mediation; sustainability; cooperation.

\section{INTRODUÇÃO}

Ao se observar o contexto das fragilidades humanas, atualmente se torna possível questionar a importância de se falar em desenvolvimento sustentável. Ao abordar o tema da sustentabilidade como um meio até mesmo de sobrevivência necessário às gerações futuras, percebe-se que se faz de extrema importância a presença de forças de cooperação, tendo em vista que o tema meio ambiente adquiriu permanente evidência ao longo dos últimos anos.

A presente pesquisa tem por finalidade avaliar como a Mediação e a Sustentabilidade trazem significado ao n. 15 dos Objetivos do Desenvolvimento Sustentável - ODS ao se consolidar a cultura da cooperação, no intuito de se verificar uma resposta ao tema proposto, com seguinte problema de pesquisa: Como a Sustentabilidade, na sua dimensão social, favorece a consolidação de uma cultura da cooperação a partir da Mediação a partir da exigência contida no Objetivo n. 15 dos Objetivos do Desenvolvimento Sustentável - ODS?

Como hipótese de pesquisa, tem-se que ao se estudar a Sustentabilidade na sua vertente social, percebe-se a reivindicação de cenários que promovam a responsabilidade e a solidariedade. Nesse caso, aparece uma segunda reivindicação: o cumprimento do Objetivo n. 15 dos Objetivos do Desenvolvimento Sustentável - ODS. Dentre as formas jurídicas de se permitir 
LINHARES, Rafaela Rovani de; AQUINO, Sergio Ricardo Fernandes de. Mediação e Sustentabilidade: por uma cultura da cooperação a partir dos objetivos do desenvolvimento sustentável. Revista Eletrônica Direito e Política, Programa de Pós-Graduação Stricto Sensu em Ciência Jurídica da UNIVALI, Itajaí, v.13, n.3, $3^{\circ}$ quadrimestre de 2018. Disponível em: www.univali.br/direitoepolitica - ISSN 1980-7791

o aperfeiçoamento de uma convivência pacífica, seja pela via institucional ou não, tem-se a alternativa da Mediação. Se o foco da Mediação é a Pessoa, percebe-se que a resolução de conflito não ocorre pela imposição da vontade estatal, mas pelas vontades que convergem em solucionar as suas dificuldades. Por esse motivo, a atitude empreendida pela Mediação não se exaure nesses espaços dialogais, porém se ampliar para a vida cotidiana. É aqui que se consolida uma cultura da cooperação.

O trabalho tem por objetivos específicos: a) identificar a importância da Sustentabilidade no século XXI; b) reconhecer a necessidade de práxis dos Objetivos do Desenvolvimento Sustentável - ODS; c) determinar o alcance da Mediação como expressão da cooperação e relacionar as diretrizes da Mediação e Sustentabilidade como forma de materialização do Objetivo n. 15 dos Objetivos do Desenvolvimento Sustentável - ODS.

A pesquisa realiza-se por meio do Método Indutivo ${ }^{3}$ e Cartesiano, da Técnica de Pesquisa Bibliográfica ${ }^{4}$, da Categoria ${ }^{5}$ e do Conceito Operacional ${ }^{6}$.

3 "[...] base lógica da dinâmica da Pesquisa Científica que consiste em pesquisar e identificar as partes de um fenômeno e colecioná-las de modo a ter uma percepção ou conclusão geral" (PASOLD, Cesar Luiz. Metodologia da pesquisa jurídica: teoria e prática. 13. ed. Florianópolis: Conceito Editorial, 2015, p. 213).

4 "[...] Técnica de investigação em livros, repertórios jurisprudenciais e coletâneas legais" (PASOLD, Cesar Luiz. Metodologia da pesquisa jurídica: teoria e prática. 13. ed. Florianópolis: Conceito Editorial, 2015, p. 215).

${ }^{5}$ Nas palavras de Pasold: "[...] palavra ou expressão estratégica à elaboração e/ou expressão de uma ideia". (PASOLD, Cesar Luiz. Metodologia da pesquisa jurídica: teoria e prática. 13. ed. Florianópolis: Conceito Editorial, 2015, p. 205).

${ }^{6}$ Reitera-se conforme o citado autor: "[...]definição para uma palavra ou expressão, com o desejo de que tal definição seja aceita para os efeitos das ideias que expomos [...]". (PASOLD, Cesar Luiz. Metodologia da pesquisa jurídica: teoria e prática. 13. ed. Florianópolis: Conceito Editorial, 2015, p. 205). 
LINHARES, Rafaela Rovani de; AQUINO, Sergio Ricardo Fernandes de. Mediação e Sustentabilidade: por uma cultura da cooperação a partir dos objetivos do desenvolvimento sustentável. Revista Eletrônica Direito e Política, Programa de Pós-Graduação Stricto Sensu em Ciência Jurídica da UNIVALI, Itajaí, v.13, n.3, $3^{\circ}$ quadrimestre de 2018. Disponível em: www.univali.br/direitoepolitica - ISSN 1980-7791

\section{A IMPORTÂNCIA DA SUSTENTABILIDADE NO SÉCULO XXI A PARTIR DOS OBJETIVOS DO DESENVOLVIMENTO SUSTENTÁVEL - ODS}

Pode-se afirmar que o progresso constante advindo dos últimos tempos, especialmente as mudanças culturais e econômicas decorrentes do século $X X$, como o surgimento de novas tecnologias, de avanços na comunicação, de técnicas industriais e demais evoluções inerentes ao processo civilizatório, inegavelmente trouxeram benefícios à vida dos homens.

Contudo, o modelo de desenvolvimento adotado pela civilização resultou na exploração desmedida da natureza, acabou por consolidar a ideia de que não há dilema entre conservação ambiental e crescimento econômico. Assim, conforme contextualiza Bauman7 "[...] vivemos em tempos difíceis, pois a própria liberdade do ser humano está em crise".

Ocorre que, em dado momento histórico, a civilização do século XXI enfrenta uma inegável busca pelo desenvolvimento sustentável, na medida em que cada vez mais se tornam complexas as relações entre as diferentes sociedades humanas e o meio ambiente. Isso porque, passou-se a enfrentar visões antagônicas quanto à capacidade de a sociedade moderna atingir o ideal e a práxis da Sustentabilidade.

É necessário destacar ao leitor e leitora qual o entendimento sobre a Sustentabilidade $^{8}$. Trata-se de expressão polissêmica, a qual inicia-se pela

\footnotetext{
${ }^{7}$ BAUMAN, Zygmunt. A ética é possível em um mundo de consumidores? Tradução: Alexandre Werneck. Rio de Janeiro: Zahar, 2011, p. 21.

8 "A Sustentabilidade não é o anúncio do 'fim de uma era' guiada pelas medidas de 'salvação' de um progresso cujo crescimento é infinito. Essa é a imagem da catástrofe, a qual Benjamin observou na pintura Angelus Novus. Não! As ações enunciadas como sustentáveis traduzem metamorfoses necessárias para se criar outras condições de vida, bem como a possibilidade de uma paz mais duradoura, cuja compreensão acerca do novo, da postura em se identificar as próprias características dos fenômenos estimula um diálogo mais aberto entre humanos e não-humanos. Esse reconhecimento aparece como a epifania de que não existe - nem existirá - a perpetuação dos seres humanos em todo o território terrestre sem a presença dos ecossistemas, da biosfera, da fauna e da flora planetária. Insiste-se: todos os seres vivos habitam a Terra porque comungam um vínculo de vida ${ }^{8}$ e dependência uns com os outros". (AQUINO, Sérgio Ricardo Fernandes de. A importância da sustentabilidade como critério de desenvolvimento do constitucionalismo latino-americano. In: AQUINO, Sérgio Ricardo Fernandes de; DE BASTIANI, Ana Cristina. As andarilhagens da sustentabilidade no século XXI. Florianópolis: Empório do Direito, 2015, p. 207/208).
} 
LINHARES, Rafaela Rovani de; AQUINO, Sergio Ricardo Fernandes de. Mediação e Sustentabilidade: por uma cultura da cooperação a partir dos objetivos do desenvolvimento sustentável. Revista Eletrônica Direito e Política, Programa de Pós-Graduação Stricto Sensu em Ciência Jurídica da UNIVALI, Itajaí, v.13, n.3, $3^{\circ}$ quadrimestre de 2018. Disponível em: www.univali.br/direitoepolitica - ISSN 1980-7791

interseção entre as dimensões econômica, social e ambiental. No entanto, amplia-se para outros fatores como o filosófico, o ecológico, o político, entre outros. Para fins deste trabalho, a categoria Sustentabilidade significa a compreensão ecosófica acerca da capacidade de resiliência entre os seres e o ambiente para se determinar - de modo sincrônico e/ou diacrônico - quais são as atitudes que favorecem a sobrevivência, a prosperidade, a adaptação e a manutenção da vida equilibrada9 .

Nesse cenário, surgiram os Objetivos do Desenvolvimento Sustentável ${ }^{10}$, os quais foram baseados nos Objetivos de Desenvolvimento do Milênio. Pode-se considerar que a formulação desses objetivos significou um grande avanço para a população mundial, pois 193 estados-membros da ONU se comprometeram a contemplar 17 objetivos, acompanhados de outras 169 metas a serem realizadas.

É evidente que os Objetivos do Desenvolvimento Sustentável representam um grande desafio para as nações, de forma que necessitam de cooperação entre todos os atores, no sentido de cuidar da Terra, principalmente no que tange sua finitude, definindo-se valores baseados em um cuidado para a preservação do meio ambiente.

O compromisso global de que tratam as diretrizes propostas pela ONU com os Objetivos do Desenvolvimento Sustentável, no tocante ao objetivo n. 15, objeto do presente estudo, tem como principal preocupação: "proteger, recuperar e promover o uso sustentável dos ecossistemas terrestres, gerir de forma sustentável as florestas, combater a desertificação, deter e reverter a degradação da terra e deter a perda de biodiversidade ${ }^{11 "}$.

\footnotetext{
${ }^{9}$ Conceito Operacional elaborado pelos Pesquisadores deste artigo.

10 ONU. Programa das Nações Unidas para o Desenvolvimento. Os Objetivos de Desenvolvimento Sustentável: dos ODM aos ODS. Disponível em: <http://www.pnud.org.br/ods.aspx>. Acesso em: 26 abr. 2017.

11 ONU. Programa das Nações Unidas para o Desenvolvimento. Os Objetivos de Desenvolvimento em: <https://nacoesunidas.org/pos2015/ods15/>. Acesso em: 26 abr. 2017.

Disponível
} 
LINHARES, Rafaela Rovani de; AQUINO, Sergio Ricardo Fernandes de. Mediação e Sustentabilidade: por uma cultura da cooperação a partir dos objetivos do desenvolvimento sustentável. Revista Eletrônica Direito e Política, Programa de Pós-Graduação Stricto Sensu em Ciência Jurídica da UNIVALI, Itajaí, v.13, n.3, $3^{\circ}$ quadrimestre de 2018. Disponível em: www.univali.br/direitoepolitica - ISSN 1980-7791

Sob essa perspectiva, para o homem gerir ações, seja no desenvolvimento da sociedade de forma sustentável ou qualquer outra, precisa considerar a fragilidade da vida e do próprio universo. O destino do homem está diretamente ligado à natureza, não apenas por questão de sobrevivência física, como também por se tratar da integridade de sua essência.

A humanidade, diante das incertezas de sua capacidade de se submeter aos preceitos de prudência ecológica, precisa determinar o que deve ser valorizado. Necessário se faz um pensamento além de conservação, preservação e regeneração da natureza, principalmente porque se tem como imprescindível o respeito recíproco: às pessoas, ao meio ambiente e a todos os seres vivos.

Para que haja essa condição, é preciso exercitar uma cultura da cooperação que permita a reflexão coletiva e a reflexão pessoal, com a superação do paradigma do homem intolerante, cheio de verdades completas, as quais impedem a possibilidade de sentir com o outro, no sentido de que se vive em um mundo desgastado, no qual é preciso uma sensibilidade que efetue a experiência da esperança, no sentido de uma nova compreensão de mundo, regida pela cooperação.

\section{A FACE DA SOCIALIDADE DA MEDIAÇÃO}

A mediação, em um primeiro momento, foi proposta com o escopo de reduzir os conflitos e alcançar o acordo judicial. Entretanto, tem-se compreendido como seus efeitos exercem uma função transformativa entre as pessoas envolvidas. Nessa linha de pensamento, percebe-se que acaba por diminuir as diferenças entre todos, reestabelecendo as relações de confiança e entendimento, alcançando um acordo que seja, de fato, satisfatório para ambas. Para tanto, deve-se desenvolver a possibilidade de diálogo e de escuta.

O filósofo Warat pondera que, hoje, o Direito vive um momento delicado, tendo em vista que a sociedade não se sensibiliza mais com o Outro. Essa postura 
LINHARES, Rafaela Rovani de; AQUINO, Sergio Ricardo Fernandes de. Mediação e Sustentabilidade: por uma cultura da cooperação a partir dos objetivos do desenvolvimento sustentável. Revista Eletrônica Direito e Política, Programa de Pós-Graduação Stricto Sensu em Ciência Jurídica da UNIVALI, Itajaí, v.13, n.3, $3^{\circ}$ quadrimestre de 2018. Disponível em: www.univali.br/direitoepolitica - ISSN 1980-7791

deve ser resgatada para que se desenvolva uma concepção emancipatória do Direito, cuja essência é a alteridade, pois "a alteridade é a possibilidade de conhecer a existência do outro. Eu existo na medida em que tenho a capacidade para reconhecer a existência do outro, e ele comporá a minha própria existência ${ }^{12 "}$.

O citado autor propõe a volta do olhar para dentro, como busca da sabedoria da existência. Nesse sentido, a mediação Waratiana desvela-se, nas palavras do autor, como algo muito simples:

[...] tão simples que passa despercebido. Não digo tentemos entendê-lo, pois não podemos entendê-lo. Muitas coisas em um conflito estão ocultas, mas podemos sentilas. Se tentarmos entendê-las, não encontraremos nada, corremos o risco de agravar o problema. Para mediar, como para viver, é preciso sentir o sentimento. O mediador não pode se preocupar por intervir no conflito, transformálo. Ele tem que intervir sobre os sentimentos das pessoas, ajudá-las a sentir seus sentimentos, renunciando a interpretação. Os conflitos nunca desaparecem, se transformam; isso porque, geralmente, tentamos intervir sobre o conflito e não sobre o sentimento das pessoas. Por isso, é recomendável, na presença de um conflito pessoal, intervir sobre si mesmo, transformar-se internamente, então, o conflito se dissolverá (se todas as partes comprometidas fizerem a mesma coisa). O mediador deve entender a diferença entre intervir no conflito e nos sentimentos das partes. $O$ mediador deve ajudar as partes, fazer com que olhem a si mesmas e não ao conflito, como se ele fosse alguma coisa absolutamente exterior a elas mesmas. Quando as pessoas interpretam (interpretar é redefinir), escondem-se ou tentam dominar (ou ambas as coisas). Quando as pessoas sentem sem interpretar, crescem ${ }^{13}$.

A percepção do Outro pelas suas próprias características e o seu reconhecimento como "ser próprio" é uma tarefa difícil porque demanda um

12 WARAT, Luis Alberto. Direito, sujeito e subjetividade: para uma cartografia das ilusões. Captura Críptica: direito política, atualidade. Revista Discente do Curso de Pós-Graduação em Direito, n.2., v.2. Florianópolis, Universidade Federal de Santa Catarina: 2010. Disponível em:< http://capturacriptica.ccj.ufsc.br/>. Acesso em: 10 abr. 2017.

13 WARAT, Luis Alberto. O Ofício do Mediador. Florianópolis: Fundação Boiteux, 2004, p. 26. 
LINHARES, Rafaela Rovani de; AQUINO, Sergio Ricardo Fernandes de. Mediação e Sustentabilidade: por uma cultura da cooperação a partir dos objetivos do desenvolvimento sustentável. Revista Eletrônica Direito e Política, Programa de Pós-Graduação Stricto Sensu em Ciência Jurídica da UNIVALI, Itajaí, v.13, n.3, $3^{\circ}$ quadrimestre de 2018. Disponível em: www.univali.br/direitoepolitica - ISSN 1980-7791

gradual abandono das posturas excessivamente egoístas. A promoção do estar-junto pela mediação envolve responsabilidade, compromisso, cuidado e cooperação. Resgata-se o sentido da Socialidade, da vida comunitária, algo que Estado, na sua função judicial ${ }^{14}$, nem sempre consegue trazer as respostas mais satisfatórias.

Ao se entender a necessária práxis da Socialidade pelas diferentes formas de mediação, constata-se, mais e mais, a força da cooperação, especialmente quando o espaço do mediar se amplia para além de dois egos envolvidos. Precisa-se de uma genuína ecosofia do sensível ${ }^{15}$. A sua força constitutiva para as relações humanas e não humanas é capaz de formular ações políticas para se assegurar, num primeiro momento, modos de convivência pacíficos e, após, formular regras jurídicas a fim se poder reivindicar esse comportamento como pressuposto de nosso desenvolvimento civilizacional comum.

\section{MEdiAÇÃo e SUSTENTABilidade: A COOPERAÇÃo VIVA PELO SIGNIFICADO DO OBJETIVO N. 15 DOS OBJETIVOS DO DESENVOLVIMENTO SUSTENTÁVEL}

Mediação e Sustentabilidade não são apenas experiencias que contribuem para a nossa perpétua humanização. Ambas categorias sugerem uma atitude maior, cujos resultados não são imediatos, porém necessitam ser entendidos e praticados na vida de todos os dias. Sob igual argumento, reivindicam uma condição ecológica para se estabelecer uma situação de equilíbrio entre os

14 "[...] tomar para si o monopólio da jurisdição, determinando o Direito ao caso concreto de forma impositiva, o Estado pretende tratar o conflito por meio da aplicação do Direito positivo. Por conseguinte, a jurisdição aparece como uma atividade na qual o Estado substitui as partes num modelo baseado em princípios expressos na própria lei e universalmente reconhecidos". (SPENGLER, Fabiana Marion. Da jurisdição à mediação: por uma outra cultura no tratamento de conflitos. Ijuí, (RS): UNIJUÍ, 2010, p. 107).

15 "A ecosofia do sensível, [...], devolve toda sua importância ao afeto, será a partir de então uma alternativa ao que foi a 'normopatia' moderna. Esta, seja ela de obediência religiosa, moral ou política (sua lógica é idêntica: 'dever-ser'), se dedica a evacuar todo risco: ideologia do 'risco zero', para garantir com exagero, asseptizando a existência quotidiana até torná-la incapaz de resistir à intrusão de anticorpos ou às diversas adversidades, no entanto, constitutivas do dado mundano. Ora, é bem conhecido que o medo dos abusos, dos excessos, na verdade, da desordem, [...] conduz ao imobilismo mais embrutecedor". (MAFFESOLI, Michel. Homo eroticus: comunhões emocionais. Tradução de Abner Chiquieri. Rio de Janeiro: Forense, 2014, p. 246) 
LINHARES, Rafaela Rovani de; AQUINO, Sergio Ricardo Fernandes de. Mediação e Sustentabilidade: por uma cultura da cooperação a partir dos objetivos do desenvolvimento sustentável. Revista Eletrônica Direito e Política, Programa de Pós-Graduação Stricto Sensu em Ciência Jurídica da UNIVALI, Itajaí, v.13, n.3, $3^{\circ}$ quadrimestre de 2018. Disponível em: www.univali.br/direitoepolitica - ISSN 1980-7791

envolvidos. O conhecimento produzido e as ações empreendidas denotam uma perspectiva ecosófica ${ }^{16}$.

Ao se debater, por exemplo, as condições de Mediação Comunitária ${ }^{17}$ percebese quais interesses comuns entre as pessoas são vitais, indispensáveis para se desenvolver atitudes políticas que se transformam em Políticas Públicas. Nesse caso, ao se compreender a dimensão ecológica da Sustentabilidade por meio da Mediação, destaca-se a força da cooperação para se manter estilos de organização social que reconhecem o valor da interdependência entre as diferentes vidas. A desejada paz nasce pelo reconhecimento da diferença entre seres e ambientes.

No entanto, para que ambas categorias - Mediação e Sustentabilidade - tragam sentido vivo e cumprimento ao que se refere o enunciado do Objetivo n. 15 dos Objetivos do Desenvolvimento Sustentável, essa cooperação deve ser exercitada a partir de uma exigência republicana esquecida, qual seja, a Fraternidade ${ }^{18}$.

${ }^{16}$ A proposição da Ecosofia em Guattari é essa articulação ético-política entre três registros ecológicos: o ambiental, o das relações humanas e o da subjetividade humana. Segundo o mencionado autor, somente nessa interação - conflituosa, trágica - entre o "Eu" interior (subjetividade) e o mundo exterior "[...] - seja ela social, animal, vegetal, cósmica - que se encontra assim comprometida numa espécie de movimento geral de implosão e infatilização regressiva. A alteridade tende a perder toda a aspereza". (GUATTARI, Félix. As três ecologias. Tradução de Maria Cristina F. Bittencourt. Campinas, (SP): Papirus, 1990, p. 8).

17 "A mediação comunitária emerge como uma nova maneira de olhar o conflito, que propicia uma real revolução no modo como o acesso à justiça é encarado, na relação entre as partes e na sociedade como um todo, uma vez que almeja o tratamento da controvérsia, a prevenção da má administração dos conflitos, a inclusão social e a convivência pacífica. Tais mudanças ocorrem porque ela trabalha o pluralismo de valores e os diversos sistemas de vida a partir da abertura/reabertura dos canais de comunicação interrompidos. Logo, o diálogo transformador e a participação das partes na construção de um consenso visam tão somente a robustecer os laços comunitários destruídos". (WüST, Caroline. Mediação comunitária e acesso à justiça: as duas faces da metamorfose social. Santa Cruz do Sul, (RS): Essere nel Mondo, 2014, p. 91)

18 "Ora, a Fraternidade, ideia muito subtil, precisa de, com maior dos cuidados, passar para a ribaltas das preocupações futuras da ágora. E a República com novo fôlego deverá fazer disso uma (senão mesmo a principal) bandeira. Porque a Fraternidade, e só ela, é capaz de arbitrar e superar os mesmos conflitos entre a Liberdade e Igualdade, que dominaram ('Liberalismos' vs 'Socialismos') o debate do século passado". (CUNHA, Paulo Ferreira da. Nova teoria do Estado: Estado, república e constituição. São Paulo: Malheiros, 2013, p. 300) 
LINHARES, Rafaela Rovani de; AQUINO, Sergio Ricardo Fernandes de. Mediação e Sustentabilidade: por uma cultura da cooperação a partir dos objetivos do desenvolvimento sustentável. Revista Eletrônica Direito e Política, Programa de Pós-Graduação Stricto Sensu em Ciência Jurídica da UNIVALI, Itajaí, v.13, n.3, $3^{\circ}$ quadrimestre de 2018. Disponível em: www.univali.br/direitoepolitica - ISSN 1980-7791

As forças de cooperação entre humanos e a teia da vida ${ }^{19}$, conforme se constata pela leitura do Objetivo n. 15 dos Objetivos do Desenvolvimento Sustentável, não pode ocorrer se as exigências, mesmo as comunitárias, se desenvolvem sob os fundamentos industriais, consumistas, econômicos, antiéticos, corruptos, estéticos, ou seja, a partir de algo que exclua qualquer ser e/ou ambiente dessa comunhão vital.

O agir pela cooperação demanda uma Fraternidade Ecosófica, própria das atitudes solidárias do século XXI. Essa nova condição de se avaliar a importância do espírito fraterno nas exigências republicanas constitucionais da solidariedade ${ }^{20}$ não se preocupa exclusivamente com os seres humanos, como se observa a inspiração da época do Iluminismo.

Se Mediação e Sustentabilidade demandam uma Ecosofia do Sensível, tem-se, para esse século XXI, a necessidade de um Iluminismo Sensível21. É a partir

19 "Compreender a natureza da vida a partir de um ponto de vista sistêmico significa identificar um conjunto de critérios gerais por cujo intermédio podemos fazer uma clara distinção entre sistemas vivos e não-vivos. Ao longo de toda história da biologia, muitos critérios foram sugeridos, mas todos eles acabavam se revelando falhos de uma maneira ou de outra. No entanto, as recentes formulações de modelos de auto-organização e a matemática da complexidade indicam que hoje é possível identificar esses critérios. A idéia-chave da minha síntese consiste em expressar esses critérios em termos das três dimensões conceituais: padrão, estrutura e processo". (CAPRA, Fritjof. A teia da vida: uma nova compreensão científica sobre os sistemas vivos. Tradução de Newton Roberval Eichemberg. São Paulo: Cultrix, 2006, p. 135).

20 "[...] el Estado puede actuar y que es el de las causas (condiciones y obstáculos) de la libertad y la igualdad. Es un ámbito tan amplio que es prácticamente de competencia ilimitada, como es propio del Derecho en el Estado social; tan profundo que es la expresión constitucional de los que antes teorizó acerca de la actuación del principio sobre el modo de producción capitalista, causante ultimo de las exigencias de Solidaridad, lo que no deja de plantear dudas por el posible conflicto con la también protección constitucional de los elementos de ese modo de producción, como antes se vio, y que, en último término, viene a ser la expresión constitucional de la contradicción propia del constitucionalismo del Estado social; y de un nivel tal, que hace referencia a valores superiores del Ordenamiento jurídico (la libertad y la igualdad), lo que exige su prioritaria referencia y necesaria relativización a los mismos, de todo los demás". (MARTÍN, Carlos de Cabo. Teoría constitucional de la solidaridad. Madrid: Marcial Pons, 2006. p. 106)

${ }^{21}$ Fenômeno histórico no qual sugere, continuamente e de modo crítico21, a (des)constituição, a indagação e a criação dos saberes que erigem as relações entre as pessoas todos os dias - sejam sociais, profissionais, institucionais. Não se estabelece um período de tempo para sinalizar o início e fim dessa expressão, pois sua função não é determinada, de modo específico, para um momento histórico, mas, no seu decorrer, rememorar o que significa ser humano em seus múltiplos diálogos. Integra-se o lúdico e a coerência lógica, admite-se a pluralidade de fenômenos capazes de comporem os matizes do domínio científico, social, tecnológico, político, entre outros. Transita-se no ir e vir do relacionar-se e comunicar-se, nas diferentes redes de interação humana, para encontrar o que se torna fundamental ao conviver diário. 
LINHARES, Rafaela Rovani de; AQUINO, Sergio Ricardo Fernandes de. Mediação e Sustentabilidade: por uma cultura da cooperação a partir dos objetivos do desenvolvimento sustentável. Revista Eletrônica Direito e Política, Programa de Pós-Graduação Stricto Sensu em Ciência Jurídica da UNIVALI, Itajaí, v.13, n.3, $3^{\circ}$ quadrimestre de 2018. Disponível em: www.univali.br/direitoepolitica - ISSN 1980-7791

desses pressupostos que a Fraternidade se amplia entre humanos e seu reconhecimento da Natureza como "ser próprio" e favorece a consolidação da cooperação e solidariedade na elaboração desse momento presente e futuro desejáveis.

A exigência republicana da Fraternidade, encarnada no dia a dia pela cooperação e solidariedade, permitem diferentes concepções, diferentes racionalidades, diferentes linguagens de como Mediação e Sustentabilidade asseguram essa dimensão de proximidade entre as pessoas, rememorando-as dessa necessidade de um cumprimento da obrigação moral e ética entre seus semelhantes e, ainda, com os seres e ambientes que habitam a Terra.

Na medida em que esses interesses, sempre em conflito, são solucionados pela concepção ecosófica da Mediação, é possível que, aos poucos, o Objetivo n. 15 dos Objetivos do Desenvolvimento Sustentável não seja apenas uma diretriz vazia, mas aquela na qual assegura, na sua integralidade, o direito à existência.

\section{CONSIDERAÇÕES FINAIS}

Verifica-se, a partir da leitura dos argumentos apresentados neste artigo, que a hipótese de pesquisa fora confirmada, pois o cumprimento do objetivo n. 15, dos Objetivos de Desenvolvimento Sustável torna-se viável, na medida em que a vertente social da sustentabilidade promova a responsabilidade $\mathrm{e}$ a solidariedade desveladas pela mediação, a qual tem por foco a pessoa, representando um importante mecanismo de solução de dificuldades.

Dessa forma, por meio da mediação, desse espaço construído para se ampliar o diálogo na vida cotidiana, se traduz uma cultura da cooperação, cada vez mais necessária para manter o vínculo antropológico comum rumo à sustentabilidade.

A formação de uma sociedade capaz de preservar o meio ambiente ecológico demanda o reconhecimento do ser humano compreensivo, capaz de chegar a 
LINHARES, Rafaela Rovani de; AQUINO, Sergio Ricardo Fernandes de. Mediação e Sustentabilidade: por uma cultura da cooperação a partir dos objetivos do desenvolvimento sustentável. Revista Eletrônica Direito e Política, Programa de Pós-Graduação Stricto Sensu em Ciência Jurídica da UNIVALI, Itajaí, v.13, n.3, $3^{\circ}$ quadrimestre de 2018. Disponível em: www.univali.br/direitoepolitica - ISSN 1980-7791

um consenso, consciente de que as dificuldades enfrentadas pela modernidade no tocante aos desafios do desenvolvimento sustentável, não podem constituir um óbice à realização das ações ecologicamente corretas.

De acordo com os dados constantes na página eletrônica dos Objetivos de Desenvolvimento Sustentável, tem-se como ações implementadas atinentes ao n. 15 dos Objetivos de Desenvolvimento Sustentável: a criação de projetos para Prevenção e Controle do Desmatamento na Amazônia, o projeto de Conservação e Utilização Sustentável da Diversidade Biológica Brasileira (Probio), a Economia dos Ecossistemas e da diversidade, dentre outros 22.

É por meio do diálogo, como característica fundamental da mediação, que se tem a viabilidade para avançar em um possível cenário concreto, proposto pelos Objetivos de Desenvolvimento Sustentável, para viabilizar a conservação da Terra, considerando sua finitude e os severos impactos por ela suportados ao longo dos anos.

\footnotetext{
22 Sobre os dados do site dos Objetivos de Desenvolvimento Sustentável: "O Ministério do Meio Ambiente (MMA) possui Planos de Ação para a Prevenção e Controle do Desmatamento na Amazônia Legal, no cerrado e na caatinga. Também está em vigor, na mesma pasta, o Projeto de Monitoramento do Desmatamento nos Biomas Brasileiros por Satélite, realizado em parceria com o Instituto Brasileiro do Meio Ambiente e dos Recursos Naturais Renováveis (Ibama) e apoio do Programa das Nações Unidas para o Desenvolvimento (Pnud). O Brasil conta ainda com diretrizes em uma Política Nacional de Biodiversidade (PNB) e com um Plano de Implementação da Política (PAN-Bio). O Projeto de Conservação e Utilização Sustentável da Diversidade Biológica Brasileira (Probio), por sua vez, identifica ações prioritárias, estimula subprojetos que promovam parcerias entre os setores públicos e privados, gerando e divulgando informações e conhecimentos na temática da biodiversidade. Quanto à integração da biodiversidade ao desenvolvimento sustentável, há iniciativas em andamento, como o Projeto TEEB Regional-Local. A sigla vem do inglês de The Economics of Ecosystems and Biodiversity, que quer dizer, em tradução livre, A Economia dos Ecossistemas e da Biodiversidade. Trata-se de iniciativa conjunta do MMA, do Ministério da Fazenda (MF), do Ministério da Ciência, Tecnologia e Informação (MCTI), do Instituto de Pesquisa Econômica Aplicada (IPEA), do Instituto Brasileiro de Geografia e Estatística (IBGE), da Secretaria de Assuntos Estratégicos da Presidência da República (SAE-PR), do Programa das Nações Unidas para o Meio Ambiente (Pnuma), da CNI e da Conservação Internacional do Brasil (CI) em parceria com a empresa Deutsche Gesellschaft für Internationale Zusammenarbeit (GIZ), que visa identificar e ressaltar os benefícios da conservação e do uso sustentável da biodiversidade e dos serviços ecossistêmicos no país, bem como avaliar os custos de sua perda". (ONU. Programa das Nações Unidas para o Desenvolvimento. Os Objetivos de Desenvolvimento Sustentável: dos ODM aos ODS. Disponível em: <http://www.estrategiaods.org.br/os-ods/ods15/>. Acesso em 01 mai. 2017).
} 
LINHARES, Rafaela Rovani de; AQUINO, Sergio Ricardo Fernandes de. Mediação e Sustentabilidade: por uma cultura da cooperação a partir dos objetivos do desenvolvimento sustentável. Revista Eletrônica Direito e Política, Programa de Pós-Graduação Stricto Sensu em Ciência Jurídica da UNIVALI, Itajaí, v.13, n.3, $3^{\circ}$ quadrimestre de 2018. Disponível em: www.univali.br/direitoepolitica - ISSN 1980-7791

\section{REFERÊNCIA DAS FONTES CITADAS}

AQUINO, Sérgio Ricardo Fernandes de. A importância da sustentabilidade como critério de desenvolvimento do constitucionalismo latino-americano. In: AQUINO, Sérgio Ricardo Fernandes de; DE BASTIANI, Ana Cristina. As andarilhagens da sustentabilidade no século XXI. Florianópolis: Empório do Direito, 2015.

BAUMAN, Zygmunt. A ética é possível em um mundo de consumidores? Tradução: Alexandre Werneck. Rio de Janeiro: Zahar, 2011.

CAPRA, Fritjof. A teia da vida: uma nova compreensão científica sobre os sistemas vivos. Tradução de Newton Roberval Eichemberg. São Paulo: Cultrix, 2006.

CUNHA, Paulo Ferreira da. Nova teoria do Estado: Estado, república e constituição. São Paulo: Malheiros, 2013.

GUATTARI, Félix. As três ecologias. Tradução de Maria Cristina F. Bittencourt. Campinas, (SP): Papirus, 1990.

MAFFESOLI, Michel. Homo eroticus: comunhões emocionais. Tradução de Abner Chiquieri. Rio de Janeiro: Forense, 2014.

MARTÍN, Carlos de Cabo. Teoría constitucional de la solidaridad. Madrid: Marcial Pons, 2006.

ONU. Programa das Nações Unidas para o Desenvolvimento. Os Objetivos de Desenvolvimento Sustentável: dos ODM aos ODS. Disponível em: <http://www.estrategiaods.org.br/os-ods/ods15/>. Acesso em 01 mai. 2017

PASOLD, Cesar Luiz. Metodologia da pesquisa jurídica: teoria e prática. 13. ed. Florianópolis: Conceito Editorial, 2015.

SPENGLER, Fabiana Marion. Da jurisdição à mediação: por uma outra cultura no tratamento de conflitos. Ijuí, (RS): UNIJUÍ, 2010.

WARAT, Luis Alberto. Direito, sujeito e subjetividade: para uma cartografia das ilusões. Captura Críptica: direito política, atualidade. Revista Discente do Curso de Pós-Graduação em Direito, n.2., v.2. Florianópolis, Universidade Federal de Santa Catarina: 2010. Disponível em:< http://capturacriptica.ccj.ufsc.br/>. Acesso em: 10 abr. 2017. 
LINHARES, Rafaela Rovani de; AQUINO, Sergio Ricardo Fernandes de. Mediação e Sustentabilidade: por uma cultura da cooperação a partir dos objetivos do desenvolvimento sustentável. Revista Eletrônica Direito e Política, Programa de Pós-Graduação Stricto Sensu em Ciência Jurídica da UNIVALI, Itajaí, v.13, n.3, $3^{\circ}$ quadrimestre de 2018. Disponível em: www.univali.br/direitoepolitica - ISSN 1980-7791

WARAT, Luis Alberto. O Ofício do Mediador. Florianópolis: Fundação Boiteux, 2004, p. 26.

WÜST, Caroline. Mediação comunitária e acesso à justiça: as duas faces da metamorfose social. Santa Cruz do Sul, (RS): Essere nel Mondo, 2014.

Recebido em: 14/08/2018

Aprovado em: 25/08/2018 